\title{
PRODUKTIEF TAALGEBRUIK BIJ HET LEREN VAN ENGELS MET IT'S-ENGLISH
}

\author{
G. Kanselaar, W.A.M. Kok, M.A.P. Giezeman, \\ J. Jaspers, H.M. Wichmann \\ Vakgroep Onderwijskunde RUU \\ ISOR, Afdeling Onderwijsonderzoek
}

\section{Uitgangspunten ${ }^{1}$}

Het doel van het project is het creëren van een computerondersteunde leeromgeving voor communicatief vreemde talenonderwijs (Kanselaar en Van Maanen, 1987). Communicatief vreemde talenonderwijs richt zich op het receptief en produktief beheersen van een vreemde taal in alledaagse situaties. Deze vorm van taalonderwijs vermijdt het geven van de vertaling als enige of meest belangrijke manier van betekenisoverdracht. Vocabulaire wordt geleerd aan de hand van contextzinnen en betekenissen in de tweede taal, zodat zich een apart taalsysteem ontwikkelt, los van de moedertaal. Daarbij zijn naast de syntactische en morfologische kenmerken van woorden, ook hun uitspraak en de zinsmelodie van groot belang. De klank van een nieuw woord is een basaal element in de betekenistoekenning aan dat woord. Om dit te realiseren zijn een groot aantal woorden en zinnen op een CD-Rom geplaatst. Het doel van communicatief taalonderwijs wordt vooral bereikt door de leerlingen de vreemde taal produktief te laten oefenen. Om vrije taalinvoer mogelijk te maken is voor het programma een parser ontwikkeld. Deze parser maakt voor de grammaticale informatie gebruik van het woordenboek dat op de CD-Rom staat. Het geheel van woordenboek, verklanking van woorden en parser maakt het mogelijk verschillende receptieve en produktieve oefeningen in deze intelligente leeromgeving te realiseren.

Het programma "IT'S-English" richt zich primair op het leren van vocabulair. Het is als Intelligent Tutorieel Systeem echter goed in te zetten bij het schrijfonderwijs. Hierna wordt eerst het programma beschreven, vervolgens het onderzoek dat in twee scholen is gedaan. Bij dit onderzoek zijn alleen de receptieve en de reproduktieve oefeningen van het programma gebruikt in de klas. Voor de vrije

\footnotetext{
${ }^{1}$ Het onderzoek wordt uitgevoerd in opdracht van de Stichting Voor Onderzoek van het Onderwijs (SVO project 9104) te Den Haag en gefinancierd door de Stuurgroep Nieuwe Media van het Ministerie van Onderwijs en Wetenschappen. Het is een vervolg op twee door het INSP gefinancierde projecten, Kanselaar, e.a. 1987 en 1989.
} 
schrijfoefening moet de parser gebruikt worden en deze werkt onder Windows 386 in Prolog 2. De XT-computers op de scholen waren hiervoor niet geschikt.

\section{BESCHRIJVING VAN HET PROGRAMMA IT'S-ENGLISH}

Een computerprogramma dat aansluit bij onze uitgangspunten moet de gebruiker in staat stellen betekenisomschrijvingen en contextzinnen van woorden in het Engels op te vragen. Ook synoniemen, antoniemen, uitspraak, syntactische en morfologische gegevens van woorden moeten opvraagbaar zijn. Verder moet zo'n programma in staat zijn taalgebruik van de gebruiker te beoordelen, zodat deze ook het actief gebruik van de woordenschat in (re)produktieve oefeningen kan leren. Om deze ideeën te kunnen realiseren bestaat het programma uit diverse onderdelen:

a. Een parser (automatische zinsontleder), die controleert of vrije taalprodukties syntactisch juist zijn, of de spelling correct is, of de werkwoorden goed verbogen zijn, etc.

b. Een database op CD-ROM, waarin omschrijvingen en contextzinnen in alledaags Engels alsmede grammaticale kenmerken, synoniemen en antoniemen van ruim 70.000 woorden zijn opgenomen.

c. Een database op CD-ROM met de gedigitaliseerde uitspraak van 5000 woorden, 1200 contextzinnen en een aantal teksten om ook het fonetisch woordbeeld en de Engelse zinsmelodie te kunnen aanbieden.

d. Een database op CD-ROM van teksten uit de onderwijsmethode 'Notting Hill Gate' van Malmberg. (3de leerjaar)

e. Een oefeningengenerator, die oefeningen aanmaakt voor receptief, reproduktief en produktief taalgebruik.

f. Een feedbackgenerator, die de domeinkennis uit de parser gebruikt om door de leerling gemaakte fouten in (re)produktieve oefeningen te ontdekken en te remediren.

\section{De lexicale-component}

Collins Cobuild English Language Dictionary (COBUILD) (Sinclair, 1987) is als basis gekozen voor de lexicale database op CD-ROM. Dit woordenboek voldoet aan een aantal eisen: Het is samengesteld voor de 'non-native learner of English', bij elk woord wordt een Engelse betekenisomschrijving en een aantal verduidelijkende en authentieke gebruikscontexten gegeven. Ook wordt voor elke woordbetekenis systematische en tamelijk gedetailleerde grammaticale informatie gegeven die gebruikt wordt door de parser. De directe koppeling tussen de grammaticale informatie en de betekenisparagraaf zorgt ervoor dat van elk woord dat de parser herkent, direct de betekenis, een aantal contextzinnen en andere relevante informatie als antoniemen, synoniemen en superordinaten 
bereikbaar zijn. Een beperking is dat de 'kracht' van de parser, d.w.z. het aantal Engelse structuren dat deze kan ontleden, wordt begrensd door de grammaticale informatie die in COBUILD beschikbaar is.

\section{De CD-Rom als opslagmedium}

Aan de uitspraak van de vreemde taal kon tot voor kort bij $\mathrm{COO}$ moeilijk aandacht besteed worden vanwege de grote hoeveelheid extern geheugen die hiervoor nodig is. De komst van de CD-Rom heft deze beperking voor een groot deel op. In dit project wordt zij als opslagmedium gebruikt voor zowel gedigitaliseerde spraak als de lexicale database in de vorm van het Collins Cobuild woordenboek. De uiteindelijke keuze voor de Extended Architecture-standaard voor de CD-Rom (XA) in ons project is uitsluitend gerelateerd aan de audio component.

De belangrijkste overwegingen bij de keuze van de XA-standaard voor de audio-component zijn:

a. De kwaliteit van de verklanking dient optimaal te zijn. Met name bij het ontbreken van de hogere spraak-frequenties (3500$11000 \mathrm{~Hz}$ ) is de uitspraak van bepaalde woorden in het Engels niet meer goed te onderscheiden, terwijl min of meer subtiele klankverschillen juist samenhangen met verschillen in betekenis.

b. Voor het leren van een goede uitspraak van de vreemde taal is het van belang dat, naast de uitspraak van 'losse' woorden ook de uitspraak van woorden in zinsverband wordt aangeboden. De leerling moet ervaren dat de uitspraak van woorden wordt beïnvloed door en samenhangt met de plaats van het woord in een context en met de zinsmelodie.

De XA-standaard beantwoordt als enige volledig aan deze eisen. $\mathrm{Zij}$ voorziet in de opslag van audio-informatie die op drie niveaus van hoge kwaliteit kan worden weergegeven. De totale capaciteit is voor het middel-hoge niveau voor de losse woorden (bereik tot $12000 \mathrm{~Hz}$ ) acht uur. Bij het minst hoge niveau voor contextzinnen en teksten (bereik tot $8000 \mathrm{~Hz}$ ) wordt een ruime hoeveelheid spraak van zeer goede kwaliteit geleverd, die in ruime mate voldoet aan de gestelde eisen.

\section{DE OEFENINGEN MET HET PROGRAMMA}

\section{De oefeningengenerator}

De oefeningengenerator kan op basis van de teksten uit de database verschillende typen oefeningen genereren. Voor het programma zijn oefeningen ontwikkeld die lopen van leesoefeningen tot betrekkelijk vrije taalinvoer. Daarbij wordt de weg van receptief via reproduktief naar produktief taalgebruik gevolgd. De oefeningen kunnen in een door de docent of door de leerling bepaalde volgorde gedaan worden. 
Bij de ontwikkeling van het programma zijn tot nu toe drie typen oefeningen ontwikkeld. Deze drie zijn prototypisch voor het type gebruik dat met een dergelijk programma mogelijk is. Wij sluiten hierbij aan bij de hoofdfasen die Neuner (1981) onderscheidt in een oefeningensequentie om tot communicatief taalgebruik te komen. Vanwege de ontwikkelde parser is het toevoegen van oefeningen bij de verdere ontwikkeling van het programma relatief eenvoudig.

\section{A. Tekst lezen (receptief)}

Uit de database van teksten wordt een verhaalfragment geselecteerd. Leerlingen kunnen bij elk woord een omschrijving van dat woord in het Engels opvragen, of contextzinnen waarin het woord voorkomt. Op basis van de informatie in de kenmerkenlijst, is het mogelijk nieuwe woorden in deze tekst in inverse video weer te geven. Zodra er een tekst op het scherm is, kan de instructie gegeven worden om het woord op te zoeken in de woordenboek database. Hierbij kunnen omschrijving en context gescheiden opgevraagd, c.q. aangeboden worden.

Naast deze mogelijkheden kan de leerling van 5000 woorden en 1200 contextzinnen ook de verklanking opvragen; indien in het woordenboek aanwezig zijn ook synoniemen, antoniemen of superordinaten op te vragen.

Woorden kunnen ook van te voren door de docent gemarkeerd worden om aan te geven dat de leerling later informatie over dit woord moet opvragen. De docent kan hierbij woordspecifieke feedback van te voren opgeven.

\section{B. Gatenteksten (reproduktief).}

Bij het maken van gatenteksten zijn één of meerdere eigenschappen van een woord, zoals die door de parser vastgelegd zijn in de kenmerkenlijst, het criterium om het woord in de oefening al dan niet weg te laten. Zo kunnen gatenteksten gemaakt worden waarbij bijvoorbeeld alle voorzetsels weggelaten zijn, of alle bijvoeglijk naamwoorden. De keuze om bijvoorbeeld alle zelfstandige naamwoorden, werkwoorden, voorzetsels, bijvoeglijke naamwoorden weg te laten kan door de docent of de leerling bepaald worden. Ook kan bijvoorbeeld het werkwoordsdeel (verb phrase) van de zin weggelaten worden. Dit type invuloefening overstijgt didactisch gezien duidelijk de huidige cloze-oefeningen waarbij alleen ieder n-de woord weggelaten kan worden.

Doordat de parser ingeschakeld wordt bij de analyse van de antwoorden van de leerling, kan op verschillende soorten foutieve antwoorden gerichte feedback gegeven worden. Hierin verschilt IT'S ENGLISH van traditionele programma's, waar elk foutief antwoord, plus de mogelijke feedback hierop, vooraf bedacht en geïmplementeerd dient te worden. Het type reactie dat door IT'S ENGLISH bij invuloefeningen gegeven kan worden, is onder andere: het ingetypte antwoord is een synoniem of hoger geordend begrip; het is wel de goede woordsoort maar niet hetzelfde woord als er stond; het 
geven van informatie over mogelijke 'typefouten' op basis van een algoritme; het geven van informatie over vervoegingen en andere grammaticale kenmerken. Het is ook mogelijk hulp te geven door een contextzin uit het woordenboek te geven waaruit het in te vullen woord eveneens is weggelaten. Dit blijkt vaak zeer informatief te zijn.

\section{Vrije tekstinvoer (produktief)}

Bij deze oefening kan de leerling een verhaaltje intypen. De parser controleert zin voor zin of de invoer grammaticaal correct is. Is dit niet het geval dan wordt een feedback boodschap gegenereerd en krijgt de leerling de gelegenheid de fout te verbeteren. Het resulterende verhaaltje wordt in de teksten-database opgeslagen, en kan zo als basis voor nieuwe oefeningen gebruikt worden. Op deze manier is het bijvoorbeeld mogelijk dat leerlingen voor elkaar invuloefeningen maken. Ook bij deze produktieve oefening zijn alle hulpopties op basis van het woordenboek beschikbaar op dezelfde wijze als bij de receptieve oefeningen. De structuur van de zin is na het parsen op het scherm zichtbaar te maken in boomvorm. Deze mogelijkheid van vrije taalinvoer stelt wel hoge eisen aan de snelheid en capaciteit van de machine. Het is echter naar onze mening op dit moment een uniek programma vanwege deze mogelijkheid van vrije taalinvoer met feedback op de syntactische juistheid van de zin.

Bij schrijfonderwijs kan men zich op verschillende aspecten van het schrijven richten, op het plannen en organiseren, het formuleren of het reviseren. Dit programma biedt hulp op het niveau van de zin bij het formuleren. Een krachtig hulpmiddel is bijv. het kunnen oproepen van de contextzinnen bij een bepaald woord om het gebruik ervan in veelvoorkomende contexten te zien.

\section{Leerlingregistratie}

Het programma houdt per leerling bij welke woorden al bestudeerd zijn, welke hulp er gevraagd is en wat de resultaten zijn van de oefeningen. Deze gegevens kunnen ingezien worden door de docent.

\section{De feedbackgenerator}

De feedbackgenerator is dat deel van het programma dat, bij een door de parser geconstateerde grammaticale fout in de invoer, een juiste en passende vorm van feedback oplevert. Bij veel syntactische fouten beperkt het programma zich nog tot de mededeling dat de zin fout is. Bij een zin als: He walk in the street, kan het programma aangeven dat er bij de derde persoon enkelvoud een s achter walk hoort, maar bij veel andere fouten is het bij het backtracking mechanisme van Prolog ingewikkeld om bij te houden waar welke fout gemaakt wordt. Het kunnen opvragen van contextzinnen van 'kritische woorden' in de foute zin, kan echter al zeer veel informatie geven over het juiste gebruik van deze woorden. 


\section{Ontwikkeling van oefeningen}

De gebruiksmogelijkheden voor de leerling zowel als voor de docent om vrije tekst in te voeren voor het ontwikkelen van oefeningen zijn aanwezig. In principe kan bijvoorbeeld de docent een tekst invoeren die de leerling later gebruikt voor oefeningen. Bij het invoeren worden er twee controles uitgevoerd. De eerste is het nagaan of het woord in het lexicon met grammaticale kenmerken in de computer aanwezig is. De tweede controle is of de parser de zin kan parsen en hij deze syntactisch juist vindt. Dit is nodig om oefeningen te kunnen maken.

Bij het invoeren van een verhaal is ook de optie aanwezig om de parser uit te zetten. Er vindt dan alleen een koppeling plaats van elk woord aan de eerste betekenis ervan. De voordelen van deze optie zijn dat het invoerproces sneller verloopt, en dat teksten van elke moeilijkheidsgraad ingevoerd kunnen worden. Deze teksten kunnen alleen gebruikt worden voor receptieve oefeningen .

De generieke mogelijkheden die de parser biedt en de grote hoeveelheid informatie in de lexicale database maken het mogelijk het programma door het toevoegen van methode-specifieke teksten snel aan verschillende onderwijsmethoden aan te passen. De menusturing en de uitgebreide contextgevoelige hulp maken het programma zeer toegankelijk voor de leraar en de leerling. De eenduidige schermopbouw maken het betrekkelijk eenvoudig om te besturen. Hierbij moet echter worden opgemerkt dat alle mogelijkheden van het programma pas volledig tot hun recht komen op apparatuur die daarvoor geschikt is (Computer met 80386 processor, $25 \mathrm{Mhz}, 4 \mathrm{Mb}$ RAM, hard disk, Windows 386, Prolog 2, CDRom-XA).

\section{HET ONDERZOEK}

\section{Onderzoeksopzet}

Het onderzoek met het programma richt zich op drie vragen: 1. Op welke wijze gebruiken de leerlingen de verschillende mogelijkheden (opties) van het programma en 2. wat vinden zij van het gebruik van het programma; 3 . wat zijn de leerresultaten van het programma?

ad. 1 . Om de vraag naar het gebruik van het programma $I T^{\prime} S$ English met CD-Rom te beantwoorden is allereerst nagegaan hoe frequent leerlingen binnen de verschillende oefeningen gebruik maken van de opties die beschikbaar zijn in het programma. De gebruiksfrequentie is te beschouwen als een indicatie van de waarde die een gebruiker toekent aan een bepaalde optie.

ad 2. De indicatie van het gebruik is aangevuld met een expliciete waardering van leerlingen voor het programma IT'S-English, qua presentatievorm, bruikbaarheid, toegankelijkheid en gepercipieerde 
waarde. Het oordeel van de leerlingen is vier keer met een korte vragenlijst gemeten.

ad 3. Voor het onderzoek naar de leerresultaten van het programma IT'S-English zijn twee aspecten onderzocht. Het eerste aspect betreft het kennen en produktief kunnen gebruiken van nieuw geleerde Engelse woorden. Het tweede aspect betreft de vaardigheid van leerlingen om de betekenis van Engelse woorden uit de context te kunnen afleiden.

Om de gegevens te kunnen verzamelen die nodig waren voor het beantwoorden van de onderzoeksvragen is een experimentele onderwijsleersituatie gecreëerd, waarin delen van het 'reguliere' onderwijs in de Engelse taal werden vervangen door onderwijs met behulp van het programma IT'S-English. Het betrof hierbij met name díe delen van het onderwijs waarin het leren van nieuwe Engelse vocabulaire centraal stond.

Gedurende een periode van 8 weken is wekelijks één lesuur voor de participerende leerlingen gevuld met oefeningen met behulp van het programma IT'S-English. De eerste zes bijeenkomsten begonnen met het lezen van een tekst. Daarna werd er een cloze-oefening gemaakt. De cloze-oefening werd de eerste drie keer door de leerlingen zelf gecreëerd aan de hand van een mondelinge opdracht van de onderzoeker/docent en vervolgens ook uitgevoerd. De andere drie keer was er een cloze-oefening voorbereid door de onderzoeker/docent. In de laatste twee COO-lessen was de gang van zaken omgedraaid. Eerst werd er een cloze-oefening gemaakt en daarna kon als er nog tijd over was - de bijbehorende tekst of een andere tekst worden gelezen.

De leerlingen uit de klas die niet aan de experimentele COO-lessen deelnamen volgden tijdens de COO-lessen de gewone lessen, gegeven door de eigen docent. Hierin werden dezelfde lessen behandeld, en daarmee dezelfde woorden aangeboden, als in de COO-lessen.

Het onderwijs-experiment is uitgevoerd in $3 \mathrm{e}$ klassen van de twee scholen. Beheerstechnische redenen maakten het noodzakelijk het aantal deelnemende leerlingen te beperken. Voor deelname aan het onderzoek werd contact opgenomen met de secties Engels van twee brede scholengemeenschappen voor voortgezet onderwijs. Een school werd gekozen om het gebruik van de methode 'Notting Hill Gate', de andere om het gebruik van 'Mainstream'. Een tweede 'selectiecriterium' was de beschikbaarheid voor de experimentele onderwijsleersituatie van het computerlokaal met (tenminste) acht P.C.'s als werkstations.

Op elk van de twee scholen hebben leerlingen van één HAVO-klas en van één VWO-klas aan het experiment deelgenomen, per klas 8 leerlingen, in totaal dus 32 leerlingen. Deze vier groepen zijn op basis van voortoetsen gematched met de vier controlegroepen (vier maal acht leerlingen uit de rest van de vier klassen). 


\section{Toetsen}

De gegevens van het gebruik worden verkregen uit de logfiles waar per leerling de handelingen met de tekst zijn opgeslagen. Om de andere week is een korte vragenlijst afgenomen waarin de leerling naar zijn/haar mening werd gevraagd over aspecten van het werken met het programma.

Voor het meten van de leerresultaten zijn drie paar parallelle toetsen gemaakt. Een kennis van het te leren vocabulair (de betekenis van 20 woorden weten), een (re)produktieve toets (een cloze-tekst met 10 gaten en een lijst van 10 woorden waarbij per woord een goede Engelse zin moet worden gemaakt), en een afleidings-toets (een tekst met 20 onderstreepte, in principe onbekende woorden, waarvan de betekenis uit de context moet worden afgeleid). Van iedere toets wordt er een als voortoets en een als natoets gebruikt. De kennistoetsen en de (re)produktietoetsen zijn methodespecifiek.

\section{RESULTATEN}

\section{Het gebruik}

De eerste onderzoeksvraag heeft betrekking op de frequentie waarmee leerlingen gebruik maken van informatie over Engelse woorden die, dankzij het gebruik van een CD-Rom, als opties beschikbaar zijn in het programma IT'S-English.

Met behulp van rechte tellingen is het aantal keren vastgesteld dat leerlingen bij het maken van oefeningen een bepaalde soort informatie over Engelse woorden gebruikten en wel tijdens de vier lessen in de periode van de laatste vier weken van het onderwijsexperiment. De gegevens over de eerste vier weken worden buiten beschouwing gelaten, o.a. vanwege aanloopproblemen bij het gebruik van het programma door de leerlingen en met de hardware-configuraties in het netwerk.

\section{Receptieve oefeningen}

Het gebruik van informatie over Engelse woorden is voor leesoefeningen en voor cloze-oefeningen afzonderlijk nagegaan. Bij leesoefeningen is het gebruik, veel meer dan bij cloze-oefeningen, explorerend van karakter. Bij cloze-oefeningen wordt het gebruik van opties meer gestuurd door de weggelaten en in te vullen woorden.

In de laatste vier weken van het onderwijsexperiment zijn 48 leesoefeningen gemaakt, 22 leesoefeningen door 16 "Mainstreamleerlingen" en 26 door 16 "Notting Hill Gate-leerlingen", waarbij door de leerling een of andere vorm van informatie over Engelse woorden is opgevraagd. In totaal is er bij het lezen van teksten 469 keer een of andere soort informatie over Engelse woorden opgevraagd. Gemiddeld is dat per oefening 9,8 keer. Er is een opmerkelijk verschil tussen "Mainstream-leerlingen" en "Notting Hill Gate-leerlingen". 
Gemiddeld vragen de "Mainstream-leerlingen" bij een leesoefening minder vaak informatie op: respectievelijk 7,2 keer tegenover gemiddeld 12 keer door "Notting Hill Gate-leerlingen".

\section{Cloze-oefeningen}

Een cloze-oefening bestaat uit een zin of een tekst, waaruit woorden zijn weggelaten. De leerling moet het juiste woord invullen, waarbij hij gebruik maakt van de context van het ontbrekende woord. In de cloze-oefeningen die de leerlingen tijdens het onderwijsexperiment aangeboden kregen waren de woorden weggelaten die in de betreffende lessen als nieuw te leren Engelse woorden waren aangemerkt.

In het totaal zijn door alle leerlingen tezamen in de vier weken van het experiment 1978 woorden ingevuld. Hiervan zijn er $928(=47 \%)$ in één keer goed ingevuld. Bij het invullen van de overige $1050(=53 \%)$ woorden hebben de leerlingen verschillende soorten informatie opgevraagd die in het programma over de in te vullen Engelse woorden beschikbaar was. In iets meer dan de helft van de gevallen blijken leerlingen pas in staat om het juiste woord in te vullen als $\mathrm{zij}$ gebruik maken van de in het programma beschikbare informatie.

Tijdens het onderwijsexperiment is de volgorde van de leesoefening en van de cloze-oefening gewijzigd. In de weken 5 en 6 werd gestart met een leesoefening, gevolgd door een cloze-oefening over dezelfde tekst. In de weken 7 en 8 begonnen de leerlingen direct met de cloze-oefening. Deze verandering is aangebracht om het gebruik van de hulpmogelijkheden van het programma te bestuderen als de leerlingen niet terug kunnen vallen op het onthouden van het woord uit de leestekst dat in de clozetekst ingevuld moet worden.

Het blijkt dat in de weken 5 en 6 de leerlingen $46 \%$ van de weggelaten woorden direct correct invullen en dus bij $54 \%$ van de in te vullen woorden extra informatie opvragen. In de weken 7 en 8 wordt $50 \%$ van de ontbrekende woorden direct correct ingevuld en wordt dus bij 50\% extra informatie opgevraagd alvorens tot een correcte invulling te kunnen komen. De extra informatie die gebruikt wordt om woorden correct in te vullen is in de $7 \mathrm{e}$ en $8 \mathrm{e}$ week kleiner dan in de $5 \mathrm{e}$ en $6 \mathrm{e}$ week. Het is mogelijk dat een verschil in moeilijkheidsgraad van de teksten hierbij een rol speelt.

Bij de 1050 keer dat een woord correct wordt ingevuld ná informatie over dat woord, is in totaal 1740 keer een of andere vorm van informatie opgevraagd. Gemiddeld is dat 1,7 keer per in te vullen woord.

\section{Vergelijking tussen de typen oefeningen}

Bij leesoefeningen zijn de betekenisomschrijvingen van Engelse woorden het meest favoriet en vormen bijna de helft van alle opgevraagde informatie. Deze soort informatie lijkt bij leesoefeningen ook het meest relevant. Immers, als men een woord niet kent bij het lezen van een tekst, dan zal men allereerst op zoek gaan naar de betekenis van dit woord. Contextzinnen, die eveneens relevante 
informatie kunnen geven over de betekenis van een woord, komen ook bij de leerlingen op de tweede plaats. De overige soorten informatie worden nauwelijks gebruikt (hier en daar wellicht uit nieuwsgierigheid). Ook dit is niet vreemd. Synoniemen, antoniemen en hyperoniemen, informatie over woordsoort en woordvormen zijn geen voor de hand liggende informatiebronnen bij het achterhalen van de betekenis van een onbekend woord in een leestekst. Opvallend is wel de frequentie van het opvragen van de uitspraak van woorden in de leestekst. Voor een deel kan dit mogelijk worden verklaard door de nieuwheid van deze optie en de nieuwsgierigheid van de leerlingen.

De conclusie is dat de leerlingen op een adequate en doelgerichte manier gebruik maken van de beschikbare soorten informatie bij het lezen van Engelse teksten. Zij kiezen de soorten informatie die het meest relevant zijn met betrekking tot hun doel: het begrijpen van de Engelse tekst.

Bij cloze-oefeningen, waarbij de leerlingen weggelaten woorden moeten invullen, bestaat meer dan de helft van de opgevraagde informatie uit contextzinnen (waaruit overigens het in te vullen woord óók is weggelaten). Ook hier is weer sprake van een relevante voorkeur. Het in te vullen woord wordt zo in meerdere contexten geplaatst, naast de context zoals die in de oefening zelf is gegeven. Het afleiden van het in te vullen woord uit de betekenisomschrijving van dat woord wordt overigens ook regelmatig door de leerlingen gekozen: een-derde van alle opgevraagde informatie bij clozeoefeningen bestaat uit betekenisomschrijvingen. De overige soorten informatie wordt nauwelijks gebruikt, met uitzondering van synoniemen, die $5 \%$ van alle gevraagde informatie uitmaken. Ook dit is een relevante keuze: als je een synoniem kent van het in te vullen woord is dit woord gemakkelijk(er) te vinden.

Opnieuw mag de conclusie luiden dat de leerlingen bewust en adequaat omgaan met de beschikbare informatie en díe soorten informatie kiezen die het meest direct aanwijzingen geven welk woord moet worden ingevuld.

Dit bewuste, taakgerichte kiezen van soorten informatie door de leerlingen wordt geillustreerd door een vergelijking van de gebruikte soorten informatie bij de twee verschillende oefeningen: lezen en invullen. In figuur 1 wordt een vergelijking tussen de twee typen oefeningen en het gebruik van de hulp weergegeven.

Duidelijk is het verschil in voorkeur bij lezen en bij clozeoefeningen. De relevantie van deze voorkeuren is reeds besproken. Het feit dat de leerlingen bij verschillende oefeningen verschillende soorten informatie kiezen bevestigt opnieuw de conclusie dat de leerlingen, werkend met het programma IT'S-English, op een adequate, taakgerichte wijze omgaan met de informatie over Engelse woorden, zoals die in het programma beschikbaar is. 
Figuur 1: Het gebruik van soorten informatie bij verschillende oefeningen.

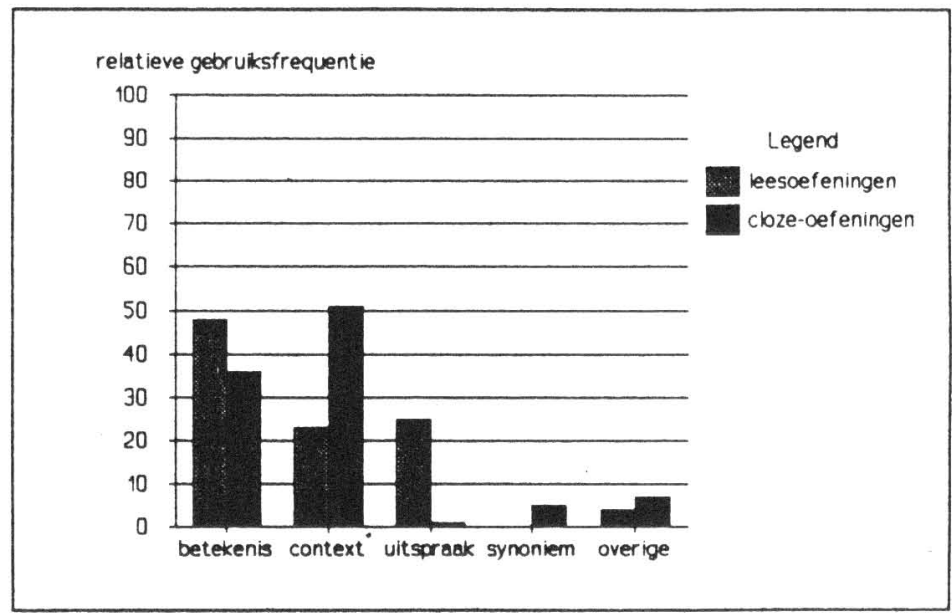

Het gebruik beoordeeld

De oordelen naar allerlei gebruiksaspecten en ook naar de leerzaamheid van het programma scoorden in het algemeen licht positief (tussen de 2 en 3 op een 5 puntsschaal). Het enige aspect dat licht negatief scoorde (tussen de 3 en 4) betrof de snelheid van het programma. Het werken met XT-computers in een netwerk levert een onvoldoende snelle reactie op bij een aantal acties. Reactietijden die langer dan 2 seconden duren gaan vrij snel irriteren. Eerder is al opgemerkt dat het volledige programma alleen op een geavanceerdere PC kan draaien.

\section{De leerresultaten}

Omdat de teksten en twee van de drie toetsen voor de beide scholen (methoden) verschillend zijn, worden de resultaten van de beide scholen op deze onderdelen afzonderlijk geanalyseerd. Om de effecten van het programma na te gaan zijn enkele multivariate covariantieanalyses uitgevoerd met de betreffende voortoets(en) als covariabelen. $\mathrm{Bij}$ de (re)produktie toetsen blijken er geen significante verschillen te zijn tussen de experimentele en controle groepen. Bij de kennis van het te leren vocabulair blijkt er bij de methode Notting Hill Gate bij de experimentele groep een significant hogere score te zijn na het gebruik van het programma in vergelijking met de controle groep en met de voormetingen als covariabele. Interessant is het hierbij te weten dat deze leerlingen relatief vaak de hulpopties van het programma gebruikten.

Significante verschillen tussen de gemiddelde scores op de toets "Afleiden van de betekenis van Engelse woorden" zijn alleen gevonden tussen HAVO-leerlingen en VWO-leerlingen, waarbij de 
VWO-leerlingen hoger scoren. Omdat gecontroleerd is voor verschillen in afleidingsvaardigheid voorafgaand aan het onderwijsexperiment betekent dit dat deze vaardigheid bij VWOleerlingen in de acht weken waarin het onderwijsexperiment plaats had méér vooruit gaat dan bij HAVO-leerlingen.

\section{Conclusie}

De hulpmogelijkheden die het programma biedt blijken door de leerlingen selectief gebruikt te worden. Bij het lezen van teksten met nieuwe woorden gebruiken zij vaker de betekenisomschrijving van het nieuwe woord, terwijl zij bij een gatentekst het juiste woord vaker proberen te vinden door contextzinnen op te vragen waarin hetzelfde woord in alledaags Engels voorkomt (waarbij dit woord in de contextzin ook is weggelaten). Dit versterkt ons idee dat het leren van woorden uit contexten bij meer produktieve oefeningen een passende methode is. Markham (1989) deed eveneens onderzoek naar het leren van woorden bij $\mathrm{COO}$ door het geven van betekenisomschrijvingen versus het aanbieden van woorden in context. Zijn conclusie is "Although definitional knowledge appears to be important in developing a basic concept of a word in the initial phases of vocabulary development, long-term, depth-oriented gains may be more closely associated with exposure to words embedded in a variety of natural paragraphs".

Aangetoond moet nog worden dat deze woorden daarna bij vrije tekstproduktie vlotter gebruikt kunnen worden. Enige evidentie hiervoor biedt het onderzoek van Van der Gein (1991) waar bleek dat een zinsopbouwcursus, waarin geoefend werd met zinspatronen om inzicht te krijgen in de relatie tussen de vorm (structuur) en de betekenis van patronen, een positief effect op de schrijfvaardigheid had.

De hardwareconfiguraties waarin dit onderzoek is gedaan maakte het niet mogelijk om de vrije tekstproduktie met de computer te onderzoeken. De eerste resultaten geven aan dat de leerlingen die met de meer communicatieve methode werkten vooruitgang in vocabulairkennis hebben geboekt in vergelijking met de controlegroep die het reguliere onderwijs gevolgd hebben. 


\section{Literatuur}

Kanselaar, G. \& T. van Maanen, Vreemde-talenonderwijs met computers in het voortgezet onderwijs: verkenning en inventarisatie van een onderzoeksgebied. In: Cluster $V$ onderwijsonderzoek: twee studies van het Instituut voor het onderzoek van het onderwijs. PSOI-reeks nr.31, 1987, pp.3-154.

Kanselaar, G., M. Giezeman, J. Jaspers, L. Koster, J. van der Veen, H. Wichmann, J. Zuidema. Computerondersteund vreemde talenonderwijs (eindverslag van SVO-project 7108). Utrecht: ISOR, Rijksuniversiteit te Utrecht, 1989.

Gein, J. van de, The sense of sentences. A study into the effects of grammar instruction upon junior writing. Proefschrift, 17 mei 1991 te Utrecht.

Markham, P. Effects of contextual versus definitional computerassisted vocabulary instruction on immediate an dlong-term vocabulary retention of advanced ESL students. Educational Psychology, vol 9(2), 121-126, 1989.

Neuner, G., M. Krüger \& U. Grewer, Übungstypologie zum kommunikativen Deutschunterricht, Berlin: Langenscheidt KG, 1981.

Sinclair, J. (Ed.), Collins COBUILD English Language Dictionary. Collins, London and Glasgow, 1987. 